\title{
MOLECULAR CHARACTERIZATION OF RESISTANCE- BREAKING TOMATO SPOTTED WILT VIRUS (TSWV) ISOLATE MEDIUM SEGMENT IN TOMATO
}

\author{
FIDAN, H. ${ }^{*}-$ SARI, N. \\ Plant Protection Department, Faculty of Agriculture, Akdeniz University \\ 07070 Antalya, Turkey \\ *Corresponding author \\ e-mail: hakanfidan@akdeniz.edu.tr \\ (Received 31 ${ }^{\text {st }}$ Dec 2018; accepted 20 $0^{\text {th }}$ Feb 2019)
}

\begin{abstract}
Tomato spotted wilt virus (TSWV) is an economically important disease causing significant yield and quality loss in tomato. The most efficient method of disease control relied on the use of the Sw-5 resistant gene. The new resistance-breaking Tswv isolates have severely infected greenhouses grown tomatoes Eastern Mediterranean area, including Antalya, Turkey. The objective of the study was to identify the cause of the resistance-breaking genetic mutations on the virus genome. The plant materials included resistant Solanum peruvianum PI126944 and four commercial hybrids, and a susceptible control. The six resistance-breaking strains (RBS) of the virus were collected from greenhouse-grown tomato plants throughout Antalya, Turkey. Beginning at the seedling stage, five consecutive inoculations were carried out at five-day intervals, using both the resistant and susceptible genotypes. The Medium segment of the virus includes the cell-to-cell movement protein (NSm) and a precursor of the surface glycoproteins (GN/GC) that were sequenced with different primer combination. The medium segment of the RBS genomes was amplified and $4825 \mathrm{bp}$ sequence aligned and blasted using NCBI database. On-structural movement (NSM) domain of the M segment consistently carried C118Y mutation in all RBS analyzed. The multiple mutations on Gc-Gn domain were not associated with resistance break down. Phylogenetic analysis indicated that RB strain identified in Turkey was closely related to Spanish RB strains. The C118Ymutation overcame the resistance conferred by the $\mathrm{Sw}-5$ gene. Hence, a new resistance source is needed to protect the tomato from new RB strains.
\end{abstract}

Keywords: orthotospoviruses, NSm protein, avrirulence determinant, hypersensitive response, Sw-5b gene

\section{Introduction}

Tomato production is under threat from viral diseases causing significant yield and quality loss all over the world (Pappu et al., 2009). One of the most common viral diseases occurs with Tomato spotted wilt virus (TSWV) on tomato. The TSWV is a member of genus Orthotospovirus, family Bunyaviridae (Adams, 2017), limits tomato production especially in greenhouses. The TSWV virus is transmitted by thrips (Thysanoptera, Thripidae), the most common vector being Frankliniella occidentalisin a persistent and circulative manner (Todd et al., 1995; Mandal et al., 2001).

Orthotospoviruses are enveloped viruses including additional protein package on their RNA genomes. The virus genome contains three RNA segments known as a tripartite RNA genome structure (Cortez et al., 2001). The TSWV has similarly three RNA parts described as small (S), medium (M), and large (L) RNAs (de Haan et al., 1991). The whole genome of TSWV codes six proteins via five different open reading frames (ORFs). The $\mathrm{M}$ and $\mathrm{S}$ RNAs have special structures where genomes are ambisense The ambisense viruses include both parts of positive and part of negative polarities in their genome (Kormelink et al., 1994; Lewandowskia and Adkins, 2005). 
The genome size of TSWV is $16.6 \mathrm{kbp}$ where small, medium and large segments are $2.9 \mathrm{~kb}, 4.8 \mathrm{~kb}$, and $8.9 \mathrm{~kb}$, respectively (de Haanet al., 1990). The $\mathrm{S}$ segment has two ORFs encoding non-structural RNA silencing suppressor (NSS) and nucleocapsid (NC) proteins (Takeda et al., 2002). The M segment produces both non-structural movement protein (NSm) and envelope glycoproteins Gn-Gc (Kormelink et al., 1994). The last L segment encodes putative RNA-dependent RNA polymerases (RdRp), such as replicase, transcriptase, nuclease, helicase, cap-binding and NTPase proteins responsible for several enzymatic functions of TSWV (de Haan et al., 1991).

TSWV is the second most destructive viral pathogen in the list of economic damage causing plant viruses (Scholthof et al., 2011). The prevention and control of the spread of TSWV is very difficult due to its vectors. For TSWV management, resistant tomato varieties carrying $S w-5$ resistance gene derived from Solanum peruvianum have extensively been used (Pappu et al., 2009). In recent years, the resistant tomato plants have been infected with TSWV in Spain (Debreczeni, 2011). Similarly, resistant-breaking TSWV isolates have been reported on genetically resistant pepper plants since 2014 in Samsun, Turkey (Deligöz, 2014). Likely, severe TSWV infections are obtained on resistant gene containing tomato varieties indicating TSWV changed its genetic structure in 2016 in Turkey (Fidan et al., 2016; Batuman et al. 2017). In order to understand the genetic cause of virulence, the study has been conducted. Hence, whole genome structure of avirulent non-resistant breaking isolates and virulent resistance-breaking TSWV isolates are compared in nucleotide sequences and possible functional mutation site(s) have been investigated.

\section{Materials and methods}

\section{Determination of the $S w-5$ gene containing $T S W V$ resistant plants}

Total genomic DNAs were extracted by DNA extraction kit (Thermo Scientific, Germany,) from the resistant Solanum peruvianum PI126944, a susceptible commercial tomato hybrid variety (Hazera 5656 (Hazera Seed), and four resistant commercial hybrids, namely Torry F1 (Syngenta), Matatu F1 (RijkZwan), TayfunF1 (De Ruiter), Swanson F1 (Seminis). The DNA samples were PCR amplified using Sw5-2 primers F-AATTAGGTTCTTGAAGCCCATCT, and RTTCCGCATCAGCCAATAGTGT as reported by Dianese et al. (2010) where the 574 bp and 500 bp amplicons representing resistant and susceptible Sw-5 alleles, respectively.

\section{Inoculations of susceptible and resistant tomato plants with TSWVAntRB isolate}

The six resistance-breaking isolates (RBS) were collected throughout Antalya, Turkey, from tomato plants grown in greenhouses. Because sequence analysis indicated the presence of single haplotype, all six RBS were mixed to inoculate the resistant and susceptible tomato samples. The resistant and susceptible samples, five plants in each replicate, were inoculated with RBS and a mock inoculation with phosphate buffer was used as a control. The inoculations were repeated five times at 5 intervals. At 15 days' post inoculations (dpi) when susceptible plant showed virus symptoms, leaf tissue was collected from mock and RBS inoculated plants. Systemic viral infection was subsequently determined by RT-PCR analysis as described previously (Dianese et al., 2010). 


\section{Genome analysis of TSWV isolates}

The TSWV isolates were collected from greenhouse-grown tomato plants in Antalya province, Turkey. The TSWV isolates originated from tomato hybrids reported to carry resistance against TSWV in 2016. The TSWV isolates were kept in $-20{ }^{\circ} \mathrm{C}$ as infected leaf material at Virology Laboratory, Plant Protection Department, Akdeniz University, Antalya, Turkey. Total RNAs were extracted from the samples using an RNA extraction Kit (K0731, Thermo-Scientific, Germany). The cDNAs of TSWV were obtained with high capacity cDNA Reverse Transcription Kit (Thermo Scientific, Germany) according to the manufacturer's instructions. The M segment specific primers (Hallwass et al., 2014 and Zhong et al., 2011) presented in Table 1 were paired (Table 2) to amplify TSWV isolates by RT-PCR analyses.

Table 1. Primer sequences representing $M$ segment of tomato spotted wilt virus (TSWV) used in RT-PCR studies (Hallwass et al., 2014)

\begin{tabular}{c|c|c|c}
\hline Segment & $\begin{array}{c}\text { Primers' } \\
\text { name }\end{array}$ & The sequence of primers from 5' to 3' & $\begin{array}{c}\text { Position in M } \\
\text { segment }\end{array}$ \\
\hline \multirow{6}{*}{} & M1 (F) & AGAGCAATCAGTGCATCAGAAATATACCTATTA & $1-36$ \\
& M2 (F) & GTAGATACAAACCATCATATCTCAAACTGG & $365-394$ \\
& M3 (R) & TCTTTATCAGCTCTGGGTGAATCAC & $771-795$ \\
& M4 (F) & CAAGGTGAGACAAATCCATAGGTGGCC & $1335-1361$ \\
& M5 (R) & TGATGAGTATGCTCATGAAGAACAAC & $1638-1663$ \\
M & M6 (F) & CAGGATCATTCAAGTTTGCAATATTTCCAG & $2268-2297$ \\
& M7 (R) & CTTATTGGGGATGTGAAGAAGCTTGG & $2566-2591$ \\
& M8 (F) & GATGTTAACCCTAAAGAGCTTCCTG & $3029-3053$ \\
& M9 (R) & GTCTCAAATGCCCATGTCTATGGCTC & $3348-3373$ \\
& M10 (F) & GTTATAGGATAATTATCTTGTGTC & $4130-153$ \\
& M11 (R) & CCAGAGGTTTATGATGATTCTGCTGAG & 45794065 \\
& M12 (R) & AGAGCAATCAGTGCAAACAAAAACCTTAATCC & $4790-4821$ \\
\hline
\end{tabular}

Table 2. Primer names and sequences used in RT-PCR studies

\begin{tabular}{c|c|c}
\hline Primers' name & The sequence of primer from 5' to 3' & $\begin{array}{c}\text { Expected amplicon } \\
\text { size }\end{array}$ \\
\hline TSWV-M-1F & AGAGCAATCAGTGCATCAGA & $955 \mathrm{bps}$ \\
TSWV-M-1R & CTTCTTCTTCAACTGATCTCTCAAG & \\
TSWV-M-2F & GCAAGCTGATAATTCCTAAAGG & $1351 \mathrm{bps}$ \\
TSWV-M-2R & AAGGAGATGACATGTCTTGGG & \\
TSWV-M-3F & CCGCATAGAAGACAGCC & $1276 \mathrm{bps}$ \\
TSWV-M-3R & GTTATAGAAGGTCCTAATGATTGCA & \\
TSWV-M-4F & GTTAACCCTAAAGAGCTTCCTG & $979 \mathrm{bps}$ \\
TSWV-M-4R & GAGAAGATCATGGGTTATTTGAT & \\
TSWV-M-5F & CTTATCCAAGAAAAATTGATGC & $1051 \mathrm{bps}$ \\
TSWV-M-5R & AGAGCAATCAGTGCAAACAAAA & \\
\hline
\end{tabular}

The amplified RT-PCR products were both run on a 1.5\% agarose gel, and stained with ethidium bromide and then visualized under UV (Integrated Biometra Gel Imager, Goettingen/(Germany)), and sequenced from both ends at HibriGen 
(Biotechnology Research, Development Industry and Trade Co. Ltd, Turkey). The M Segment were divided into smaller sequences (700 bp to $1200 \mathrm{bp}$ ) using primers (Tables 1 and 2) to yield overlapping sequences for alignments. The sequence analysis and multiple sequence alignment were carried out using Chromas (Technelsium DNA Sequencing Software Australia) and CodonCode Corporation (Florida) software. The complete $\mathrm{M}$ segment sequences were analyzed in National Center for Biotechnology Information (NCBI) using nucleotide BLAST. The agarose gel electrophoresis of $\mathrm{M}$ segment amplifications is shown in Figure 3.

\section{Results}

The plant materials used in this study were tested using Sw-5 specific molecular marker (Dianese et al., 2010). The codominant SCAR Sw5-2 marker confirmed the resistant vs susceptible status of the plant materials. The resistant Solanum peruvianum was homozygous resistant (574 bp), the four commercial hybrids were heterozygous (574 and $500 \mathrm{bp}$ ), and the susceptible one was homozygous (500 bp) as expected (Fig. 1).

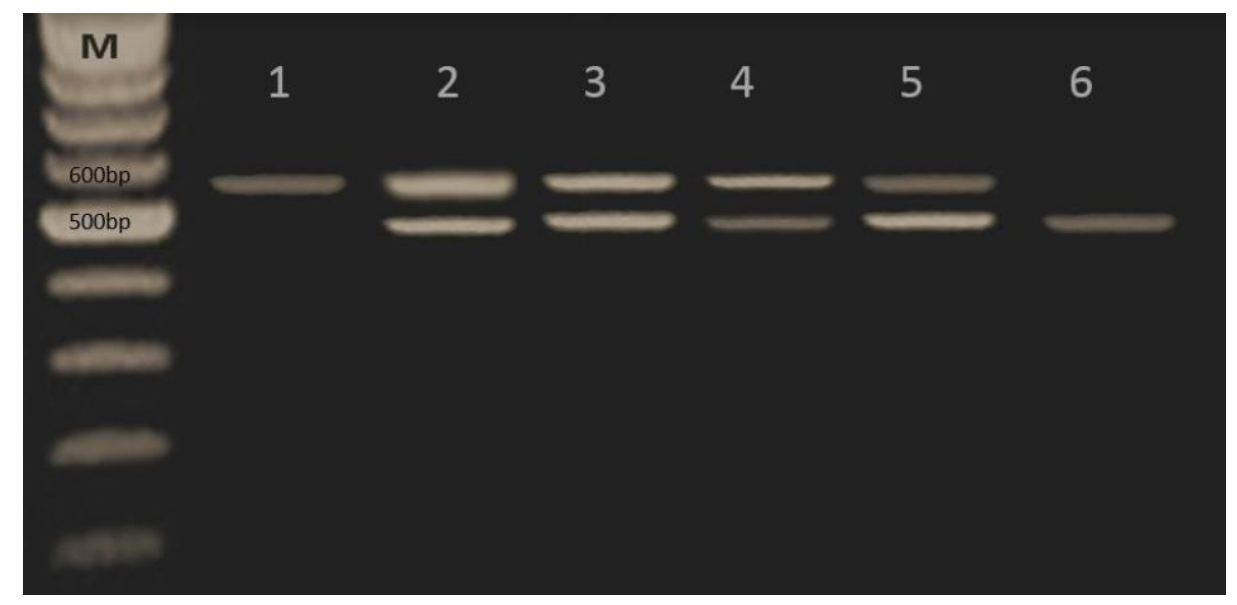

Figure 1. Agarose gel electrophoresis of Sw-5 primers. M: 100 bpDNA ladder; Lane 1 resistant Solanum peruvianum, is a source of resistance with homozygous alleles (574 bp); Lanes 2 Torry F1 (Syngenta), 3 Matatu F1 (RijkZwan), 4 Tayfun F1 (De Ruiter), and 5 Swanson F1(Seminis).

heterozygous resistant alleles known as resistant tomato varieties (574-500 bp); Lane 6 sensitive negative control. Tomato variety (Hazera 5656 (Hazera Seed)) without Sw-5 allele (500 bp)

\section{Antalya resistance-breaking (AntRB) TSWV isolates are confirmed in mechanical inoculations}

After the TSWV mechanical inoculation (Hull, 2014), first typical virus symptoms were observed at $7 \mathrm{dpi}$ on susceptible tomato variety. In resistant Solanum peruvianum and 4 commercial tomato varieties, the symptoms were barely evident at 15 dpi, similar in both homozygous and heterozygous plants.

RT-PCRs were performed at 21 dpi for 12 different tomato viruses (Alfalfa Mosaic Virus (AMV) (Saleh and Amer, 2013), Cucumber mosaic virus (CMV) (Paradies et al., 2000), Potato virus X (PVX) (Fidan et al., 2011), Potato virus Y (PVY) (Fidan et al., 2011), Tabaco Etch Virus (TEV) (Lee et al., 2011), Tobacco Mosaic Virus (TMV) 
(Kumar et al., 2011), Tomato mosaic virus (ToMV) (Kumar et al., 2011), Tomato yellow leaf curl virus TYLCV (Anfoka et al., 2008), Tomato Chlorosis Virus (ToCV) (Tiberini et al., 2010), Tomato ringspot virus (ToRSV) (Fuchs et al., 2009), Pepino Mosaic Virus (PePMV) (Ge et al., 2013) and TSWV (Adkins et al., 2005) (Fig. 2) it was confirmed that the samples were infected with only TSWV.



Figure 2. Agarose gel electrophoresis of PCR products obtained using LITSWVR and LITSWVF primers specific to TSWV. The TSWV coat protein specific primers have produced 276 bp amplicon in PCR analyses. Lanes: M: 100 bp Standard Marker; Lane 1 resistant source 'Solanum peruvianum', Lanes 2 'Torry F1' (Syngenta), 3 'Matatu F1' (RijkZwan), 4 'TayfunF1' (De Ruiter), and 5 'Swanson F1' (Seminis). Resistant varieties, Lane 6 ('Hazera 5656' (Hazera Seed)) sensitive varieties

After confirming that the samples got infected with TSWV (Fig. 2), the M domain (Medium segment) were sequenced using different primer combinations. The $4825 \mathrm{bp}$ $\mathrm{M}$ segment was amplified at five overlapping pieces (Fig. 3). The sequence of $\mathrm{M}$ Segment parts was aligned and the consensus sequence was subjected to haplotype analysis, using DnaSP 5 program (DNA Sequence Polymorphism. Universidad de Barcelona). Both sequence and haplotype analysis showed that RBS of TSWV collected in Antalya had a single haplotype (Additional file A4), which was named and deposited into NCBI as TSWVAntRB.

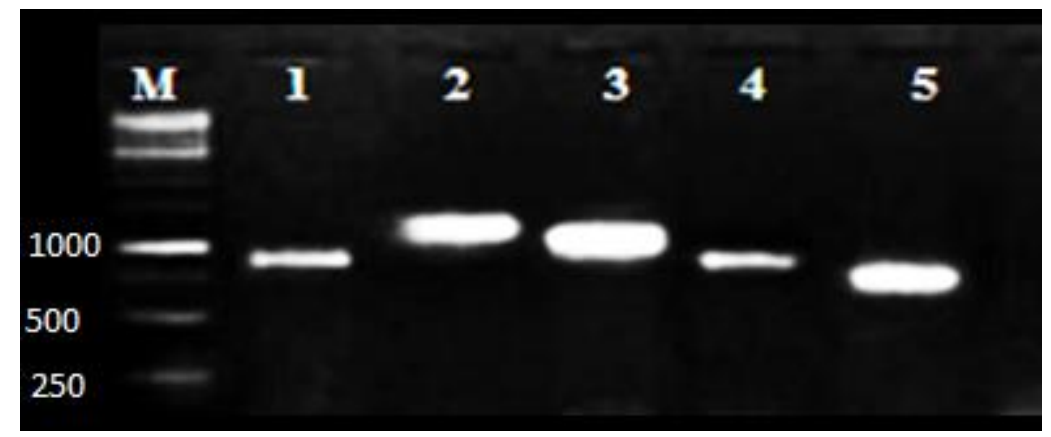

Figure 3. TSWVAntRB Medium site is belonging to agarose gel electrophoresis. M: marker, Lane 1: M1-M3 primers (759 bp), Lane 2: M2-M5 (1269 bp), Lane 3: M4-M7 primers (1230 bp), Lane 4 primers: M6-M9 primers (1082 bp), Lane 5: M-5F/M-5R-primers (1051 bp)

\section{Phylogenetic analysis of complete nucleotide sequences of the M segment}

The complete nucleotide $\mathrm{M}$ segment sequence obtained after assembly was recorded at NCBI database (MH367503). For phylogenetic analyses, the M segment sequences of 
both resistance breaking and non-breaking isolates originating from different parts of the world were retrieved from NCBI to trace the possible origin of resistance-breaking TSWVAntRB isolate. The nucleotide comparison was made in the NCBI BLAST system and the isolates with the highest similarity were selected (Table 3). Five of these isolates were RB (Resistance-breaking) and 13 of them were NRB (Non-Resistancebreaking).

Table 3. The table is nucleotide comparison made in the NCBI BLAST system and the TSWVAntRB (MH367503) with the highest similarity was selected. The first five rows are RB (Resistance-breaking) and 13 of them are NRB (Non-Resistance-breaking) isolates

\begin{tabular}{c|c|c|c|c|c|c}
\hline & $\begin{array}{c}\text { Name of } \\
\text { isolate }\end{array}$ & Region & Host & $\begin{array}{c}\text { \% } \\
\text { identity }\end{array}$ & Note & Accession No. \\
\hline $\mathbf{1}$ & TSWVAntRB & Turkey & Tomato & & RB & MH367503 \\
$\mathbf{2}$ & Pujol1TL3 & Spain & Solanum lycopersicum & 99 & RB & HM015520 \\
$\mathbf{3}$ & Sala1TL3 & Spain & Solanum lycopersicum & 99 & RB & HM015521 \\
$\mathbf{4}$ & D-191 & Australia & Tomato & 97 & RB & HM015516 \\
$\mathbf{5}$ & Borgo1 & Italy & Solanum lycopersicum & 97 & RB & MG457158 \\
$\mathbf{6}$ & CA SW21 & USA & Tomato & 94 & RB & KX898453 \\
$\mathbf{7}$ & D & USA & Tomato and Tobacco & 98 & NRB & AF208497 \\
$\mathbf{8}$ & p202/3RB & Italy & Pepper & 98 & NRB & HQ830185 \\
$\mathbf{9}$ & LK-1 & South Africa & Tomato and Amaranthus & 96 & NRB & KY250489 \\
$\mathbf{1 0}$ & GA-1L & Spain & Solanum lycopersicum & 92 & NRB & FM163371 \\
$\mathbf{1 1}$ & ALPA & Spain & Datura stramonium & 92 & NRB & HQ537114 \\
$\mathbf{1 2}$ & LS3 & South & Leonurus sibiricus & 92 & NRB & KM076652 \\
$\mathbf{1 3}$ & TSWV-YN & China & Tomato & 93 & NRB & JF960236 \\
$\mathbf{1 4}$ & YNta & China & Tobacco & 93 & NRB & KM657118 \\
$\mathbf{1 5}$ & YN5576 & China & Solanum indicum & 93 & NRB & KY495608 \\
$\mathbf{1 6}$ & SPAIN-2 & Spain & Tomato & 93 & NRB & AY744493 \\
$\mathbf{1 7}$ & BasC & USA & Ocimum basilicum & 93 & NRB & KU179514 \\
$\mathbf{1 8}$ & PA01 & USA: & Pepper & 93 & NRB & KT160281 \\
\hline
\end{tabular}

NRB: non-resistance-breaking

The phylogenetic analysis of the isolates selected from NCBI according to the Neighboring method was carried out using the Mega 7 program. The phylogenetic trees showed that the isolate TSWVAntRB is originated from Europe (Fig. 4). The genome analysis placed the virus with HM15520.1, Spanish Resistance-breaking isolate.

Of the 17 TSWV isolates with the highest similarity to the RB isolate (TSWVAntRB), five belonged to RB isolates originating from tomato reported in Spain, Italy, USA, and Australia (Table 3). The RB isolate TSWVAntRB located on the same branch with one of the Spanish RB isolates. The result indicates that the RB isolate TSWVAntRB identified in Antalya, Turkey most probably originates from Spain. TSWV isolates worldwide have been divided into two roots, Asian and European isolates (Lian et al., 2013). It was determined that the isolates divided into two separate groups and TSWVAntRB isolate was found in group II (Fig. 4). The Group II consisted of European resistance-breaking isolates. The most of Group I isolates of Asian origin. 


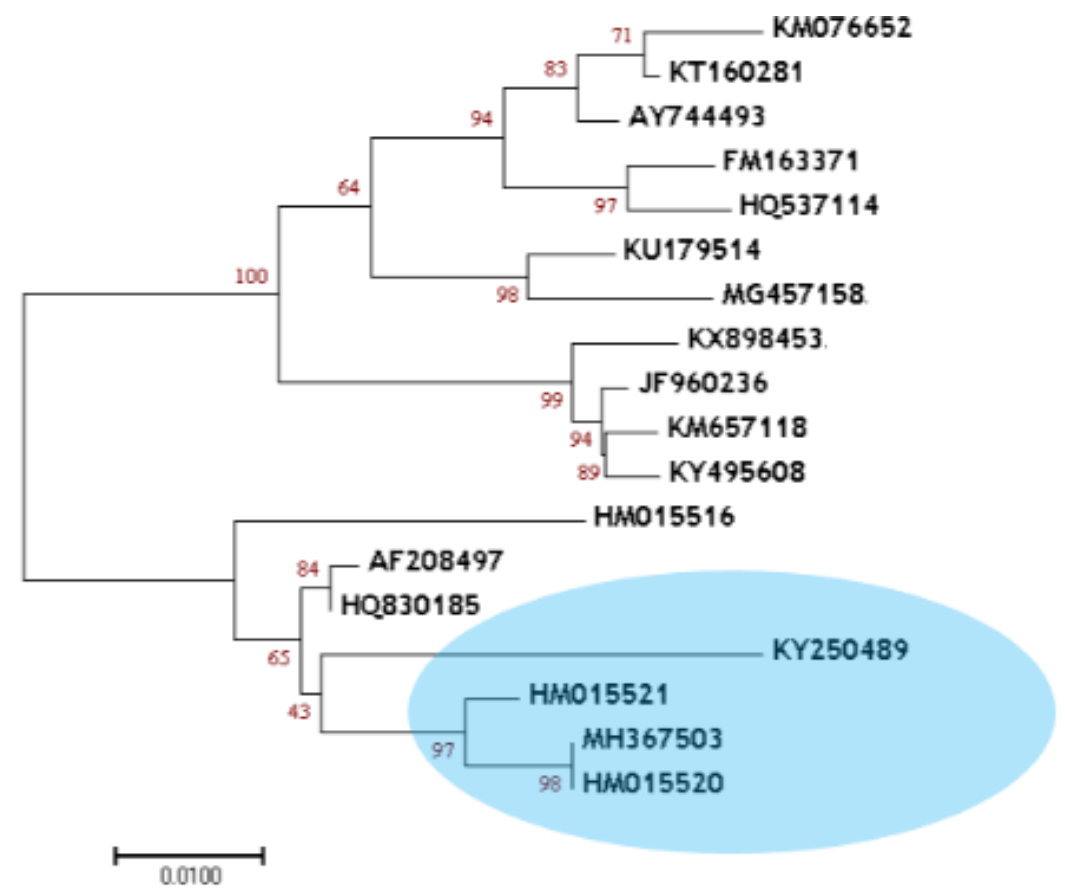

Figure 4. Phylogenetic analysis showing the relationship between TSWVAntRB (MH367503) isolates with world isolates. The phylogenetic tree MEGA7 program was created using the

Neighbor-Joining method. It was determined that the 18 isolates that were taken into consideration were formed by two groups and were calculated using the maximum composite likelihood method, which is the same root as the Spanish isolate (HM015520.1) that breaks down on the same branch with European isolates

\section{Protein-based comparisons on medium segmentation}

Worldwide studies of TSWV indicate that resistance-breaking isolates arise due to a mutation in the NSm protein responsible from cell to cell movement on the Medium segment (Lopez et al., 2011).

The Bioedit and CodonCode Aligner programs were used to process sequence data and ExPASY Tool to obtain the predicted protein sequences of the M segment (Figs. 5 and 6 ). The predicted protein sequences of the TSWVAntRB isolate and the 17 isolates were aligned on which C118Y mutation was highlighted (Fig. 5) (Additional files 1, 2). The predicted protein alignment of the $\mathrm{M}$ segment further confirmed that a single point mutation on the movement protein located on $\mathrm{M}$ segment causes the resistance to break (KY973680.1; KY973679.1, KY973677.1, KT192625.1, KT192624.1, KT192623.1, KM379142.1, KM379141.1, MH367502.1, KX618636.1, KX618635.1, KM407603).

The remaining $\mathrm{M}$ segment sequence was also analyzed. The 40 different mutations detected throughout glycoproteins $\mathrm{Gn}$ and Gc (1135 aa) were not meaningful for resistance (Additional files 3).

It was previously reported that $\mathrm{C} 118 \mathrm{Y}$ point mutation prevents the formation of HR response, causing systemic disease establishment on infected plants (Lopez et al., 2011).

The NSm protein domain on the TSWV's Medium region is the region that allows the virus to move from cell to cell. The resistance provided by the Sw-5 gene on the old isolate both causes rapid deaths in the contaminated tissues through HR reactions and there is no possibility of virus infection and contamination of new tissues in these tissues. However, it is shown that the TSWV resistance-breaking isolates related to 
NSm protein, a point mutation on the cell to cell movement gene, caused resistance breaking on TSWV resistant tomato.

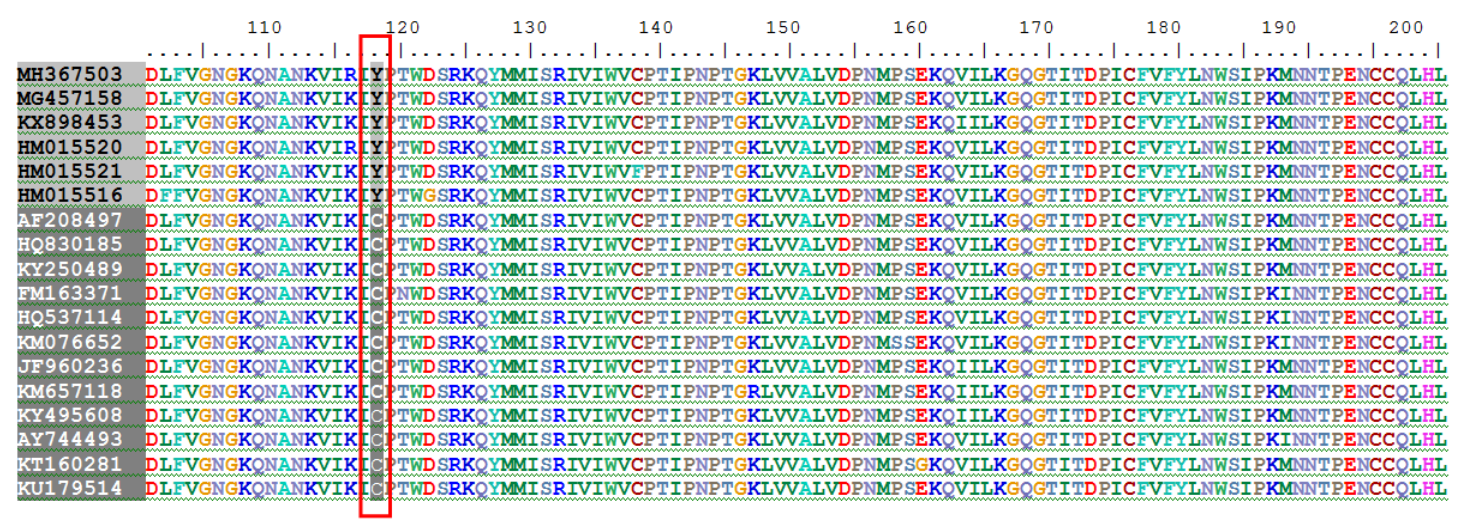

Figure 5. Sequence alignment of the NSm proteins derived from the six resistance-breaking $(R B)$ and 12 non-resistant-breaking (NRB) strains. The C118Y mutation on predicted amino acids derived from RB and NRB is indicated. The MH367503 (TSWVAntRB Antalya-Turkey RT tomato) line 2 to 6 are resistance-breaking (R.B). Lines 7 to 19 are non-resistance-breaking

(N.R.B)

\section{TSWV M Segment}

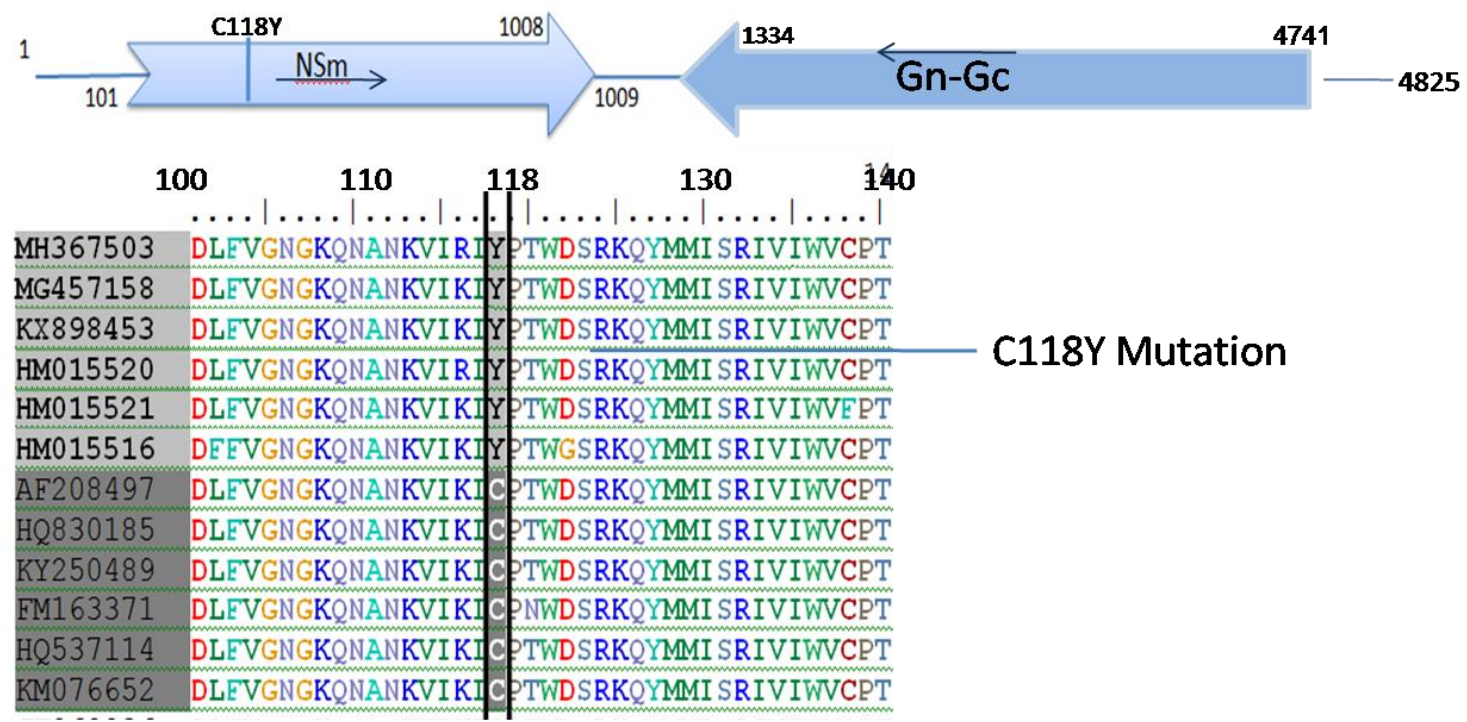

Figure 6. The mutation site in the NSm protein domain (ORF-open reading frame) of the medium segment of the TSWVAntRB isolate

Recombination events for single-stranded RNA viruses are thought to be involved in a major evolutionary process. Genetic alterations that occur due to recombination events can be very important for RNA viruses with ambisense character, which has a multisegmented structure such as TSWV. Earlier studies emphasized the emergence of new isolates due to changes in the form of point mutations on viruses with multi-segmented structures such as TSWV. 


\section{Discussion}

\section{Comparison of NCBI isolates and evaluation of the phylogenetic analysis}

The TSWV isolates were divided into two origins, namely Asia and Europe (Lian et al., 2013). The sequence comparison of $M$ segment of TSWVAntRB isolates with that of isolates in NCBI returned a similarity ratio of 93-98\%, confirming previous reports for two distinct origins (Lopez et al., 2011; Tsompana et al., 2005). However, origins of $\mathrm{RB}$ isolates are independent of sequence diversity where the same single point mutation results with resistance break. The extensive use of $\mathrm{Sw}-5$ allele may have caused positive selection, leading to the occurrence of RB isolate (de Ronde et al., 2014). The Sw-5 gene is known to provide resistance to Orthotospoviruses through HR response. When infection occurs in plants, cell death occurs rapidly via the $\mathrm{Sw}-5$ gene and the virus is trapped within the dead cells. Recent studies have informed that C118Y mutation on the NSm proteins of Orthotospoviruses fails Sw-5 protein to initiate the HR, leading to systemic virus infections in plants (Leastro et al., 2015). The NSm protein is a nonstructural protein (Kormelink et al., 1994; Storms et al., 1995) that promotes the generation of Orthotospoviruses through plasmodesmata into envelope-free nucleocapsids. Hence, the NSm protein is able to spread to neighboring healthy cells through plasmodesmata at the absence of a functional Sw-5 gene or C118Y mutation that make $\mathrm{Sw}-5$ protein fail to trigger HR.

Lopez et al. (2011) reported that $\mathrm{C} 118 \mathrm{Y}$ mutation on the NSm protein in the medium segment is a very important for adaptation on new hosts. This mutation, which is likely to occur on the cysteine, is considered to be a fundamental point in the adaptation of TSWV to the new hosts during the evolutionary process.

The TSWVAntRB may have been transported from Spain via thrips vectors. Persistent propagative transmission of the virus with thrips may explain the longdistance transmission. However, it has been noted that there is no association in the breakdown of the resistance of the TSWV isolate accumulated in thrips body (Debreczeni et al., 2014). It has been argued that the phylogenetic relationship of isolates obtained from different continent may be effective in transporting vector thrips with long-distance migration capability (Lopez et al., 2011). Knowing the factors involved in the evolution of viruses is essential to understanding the processes involved in molecular biology and epidemiology (including the emergence of new viruses), to develop more effective and strong control strategies (Garcia et al., 2001; Moya et al., 2004).

The entire genomic sequences of the Gn-Gc domain in the medium segment were also obtained and compared against the database. The result showed that although this domain carries multiple mutations, none of which plays a role in the breakdown of resistance.

Acknowledgements. The authors are thankful to the Scientific Research Projects (FLY-2017-2619) Coordination Unit of Akdeniz University.

Conflict of interests. The authors declare that they have no conflict of interests.

Ethical approval. This article does not contain any studies with human participants or animals performed by any of the authors. 


\section{REFERENCES}

[1] Adams, M. J., Lefkowitz, E. J., King, A. M. Q., Harrach, B., Harrison, R. L., Knowles, N. J., Kropinski, A. M., Kuhn, M. K. H., Mushegian, A. R., Nibert, M. et al. (2017): Changes to taxonomy and the international code of virus classification and nomenclature ratified by the international committee on taxonomy of viruses. - Archives of Virology 162: $2505-2538$.

[2] Adkins, S., Zitter, T., Momol, T. (2005): Tospoviruses (Family Bunyaviridae, Genus Tospovirus). - Fact Sheet PP-212. Plant Patology Department, Florida Cooparative Extension Services Institute of Food and Agricultural Sciences, University of Florida.

[3] Anfoka, G., Abhary, M., Haj Ahmad, F., Hussein, A. F., Rezk, A., Akad, F., AbouJawdah, Y. M., Lapidot, F., Vidavski, M. K., Nakhla, H., Sobh, H., Atamian, L., Cohen, I., Sobol, H., Mazyad, D. P., Maxwell, Czosnek, H. (2008): Survey of Tomato yellow leaf curl disease-associated viruses in the eastern Mediterranean basin. - Journal of Plant Pathology 90(2): 311-320.

[4] Batuman, O., Turini, T. A., Oliveira, P. V., Rojas, M. R., Macedo, M., Mellinger, H. C., Adkins, S. T., Gilbertson, R. L. (2017): First report of a resistance-breaking strain of tomato spotted wilt virus infecting tomatoes with the Sw-5 tospovirus-resistance gene in California. - Plant Disease 101(4): 637. https://doi.org/10.1094/PDIS-09-16-1371-PDN.

[5] Cortez, I., Saaijer J., Wongjkaew K. S., Pereira A. M., Goldbach R., Peters D., Kormelink R. (2001): Identification and characterization of a novel tospovirus species using a new RT PCR Approach. - Archives of Virology 146(2): 265-278.

[6] Debreczeni, D. E, Ruiz, S. Aramburu, C., Lopez, C., Belliure, B., Galipienso, L., Soler, S., Rubio, L. (2011): Detection, discrimination and absolute quantitation of tomato spotted wilt virus isolates using real time RT-PCR with TaqMan MGB probes. - Journal of Virological Methods 176(1-2): 32-37.

[7] Debreczeni, D. E., Rubio, L., Aramburu, J., Lopez, C., Galipienso, L., Soler, S., Belliure, B. (2014): Transmission of Tomato spotted wilt virus isolates Able and Unable To Overcome Tomato or Pepper Resistance by Its Vector Frankliniella occidentalis. Annals of Applied Biology.164(2): 182-189.

[8] de Haan, P., Wagemakers, L., Peters, D., Goldbach, R. (1990): The S RNA segment of Tomato spotted wilt virus has an ambisense character. - Journal of General Virology 71(5): 1001-1007.

[9] de Haan, P., Kormelink, R., de Oliveira, R., Van Poelwijk, F., Peters, D., Goldbach, R. (1991): Tomato spotted wilt virus L RNA encodes a putative RNA polymerase. - Journal of General Virology 72: 2207-2216.

[10] Deligoz, I. (2014): First report of resistance breaking strain of tomato spotted wilt virus (Tospovirus; Bunyaviridae) on resistant sweet pepper cultivars in Turkey. - New Disease Reports 30: 26. http://dx.doi.org/10.5197/j.2044-0588.2014.030.026.

[11] de Ronde, D., Butterbach, P., Kormelink, R. (2014): Dominant resistance against plant viruses dominant resistance against plant viruses. - Front Plant Science 5: 307.

[12] Dianese, E. C., Fonseca, M. E. N. (2010): Development of a locus-specific, co-dominant SCAR marker for assisted-selection of the Sw-5 (Tospovirus resistance) gene. Molecular Breeding 25: 133-142.

[13] Fidan, H. (2016): Antalya' da Örtü Altı Domates ve Biber Alanlarında Dayanıklılık Kıran Tomato spotted wilt virus (TSWV) İzolatların Genetik Kıyaslanması. - VI. Türkiye Bitki Koruma Kongresi KONYA, Türkiye, pp. 560-560.

[14] Fidan, H., Adak, N. A., Konuksal, A., Akerzurumlu, E., Yilmaz, M. A. (2011): Occurrence of Alfalfa Mosaic Virus (AMV) diseases on potato crops in northern Cyprus. - 5th Balkan Symposium on Vegetables and Potatoes. Tirana, Arnavutluk 960: 341-346.

[15] Fidan, H., Unlu, M., Unlu, A. (2012): Determination of Batem's melon pure lines for resistance to ZYMV. - Xth EUCARPIA International Meeting on Genetics and Breeding of Cucurbitaceae 2012, pp. 466-471. 
[16] Fuchs, M. (2009): Association of Tobacco ring spot virus, Tomato ring spot virus and Xiphinema americanum with a decline of high bush blueberry in New York. - 21st International Conference on Virus and Other Graft Transmissible Diseases of Fruit Crops, pp. 15-17.

[17] Garcia-Arenal, F., Fraile, A., Malpica, J. M. (2001): Variability and genetic structure of plant virus populations. - Annual Review of Phytopathology 39: 157-186.

[18] Ge, B., Li, Q., Liu, G., Lu, M., Li, S., Wang, H. (2013): Simultaneous detection and identification of four viruses infecting pepino by Multiplex RT-PCR. - Archives of Virology 158(6): 1181-1187.

[19] Hallwass, M., de Oliveira, A. S., Dianese, E., Lohuis, D., Boiteux, L. S., Nagata, A. K., Resende, R. O., Kormelink, R. (2014): The Tomato spotted wilt virus cell-to-cell movement protein (NSM) triggers a hypersensitive response in $S w-5$ containing resistant tomato line and in Nicotiana benthamiana transformed with the functional $S w-5 b$ resistance gene copy. - Molecular Plant Pathology 15(9): 871-880.

[20] Hull, R., (2014): Plant Virology. Chap. 4: Symptoms and Host Range. - Academic Press, Cambridge, MA, pp. 145-198. 10.1016/B978-0-12-384871-0.00004-2.

[21] Kormelink, R., Storms, M., Van, J., Peters, L. D., Goldbach, R. (1994): Expression and subcellular location of the NSM protein of tomato spotted wilt virus (TSWV), a putative Viral Movement Protein. - Virology 200(1): 56-65.

[22] Kumar, S., Udaya, Shankar, A. C., Nayaka, S. C., Lund, O. S., Prakas, H. S. (2011): Detection of tobacco mosaic virus and tomato mosaic virus in pepper and tomato by multiplex RT-PCR. - Letters in Applied Microbiology 53(3): 359-363.

[23] Leastro, M. O., Pallas, V., Resende, R. O., Sanchez-Navarro, J. A. (2015): The movement proteins (NSm) of distinct tospoviruses peripherally associated with cellular membranes and interact with homologous and heterologous NSm and nucleocapsid proteins. Virology 478: 39-49.

[24] Lee, J.-S., Cho, W. K., Choi, H., Kim, K. H. (2011): RT-PCR detection of five quarantine plant rna viruses belonging to poty and tospoviruses. - Plant Pathology 27(3): 291-296.

[25] Lewandowskoa, D. J., Adkins, S. (2005): The tubule-forming NSm protein from Tomato spotted wilt virus complements cell-to-cell and long-distance movement of Tobacco mosaic virus hybrids. - $\quad$ Virology 342(1): 26-37. https://doi.org/10.1016/j.virol.2005.06.050.

[26] Lian, S., Lee, J. S., Cho, W. K., Kim, M. K., Choi, H. S., Kim, K. H. (2013): Phylogenetic and recombination analysis of tomato spotted wilt virus. - Plos One 8: 1-11.

[27] Lopez, C., Aramburu, J., Galipienso, L., Soler, S., Nuez, F., Rubio, L. (2011): Evolutionary analysis of tomato $S w-5$ resistance-breaking isolates of tomato spotted wilt virus. - Journal of General Virology 92: 210-215.

[28] Mandal, B., Csinos, A. S., Martinez-Ochoa, N., Pappu, H. R. (2001): A Rapid and efficient inoculation method for tomato spotted wilt tospovirus. - Journal of Virological Methods 149(1): 195-198.

[29] Moya, A., Holmes, E. C., González-Candelas, F. (2004): The population genetics and evolutionary epidemiology of RNA viruses. - Nature Reviews Microbiology 2(4): 279288.

[30] Pappu, H. R., Jones, R. A. C., Jain, R. K. (2009): Global status of Tospovirus epidemics in diverse cropping systems: successes achieved and challenges ahead. - Virus Research 141: 219-236.

[31] Paradies, F., Finetti Sialer, M., Gallitelli, D., Castellano, Yilmaz, M. A., (2000): Partial characterization of cucumber mosaic virus isolates from citrus and grapevine. - Journal of Plant Pathology 82(2):133-145.

[32] Saleh, M. A., Amer, M. A. (2013): Biological and molecular variability of alfalfa mosaic virus affecting alfalfa crop in Riyadh region. - Plant Pathology 29(4): 410-417. 
[33] Scholthof, K. B., Adkins, S., Czosnek, H., Palukaitis, P. et al. (2011): Top 10 Plant Viruses in molecular plant pathology. - Mol. Plant Pathol. 12: 938-954. http://dx.doi.org/10.1111/j.1364-3703.2011.00752.x.

[34] Storms, M. H., Kormelink, R., Peters, D., Lent, J. W. M. V., Goldbach, R. W. (1995): The nonstructural NSm protein of tomato spotted wilt virus induces tubular structures in plant and insect cells. - Virology 214: 485-493.

[35] Takeda, A., Sugiyama, K., Nagano, H., Mori, M., Kaido, M., Mise, K., Tsuda, S., Okuno, T. (2002): Identification of a novel RNA silencing suppressor, NSs protein of tomato spotted wilt virus. - FEBS Lett. 532: 75-79.

[36] Tiberini, A., Tomassoli, L., Barba, M., Hadidi, A. (2010): Oligonucleotide microarraybased detection and identification of 10 major tomato viruses. - Journal of Virological Methods 168: 133-140.

[37] Todd, W., Culbreath, A. K., Chamberlin, J. R., Beshear, B. R. J., Mullinix, G. (1995): Colonization and Population Dynamics of Thrips in Peanuts in the Southern United States. - In: Parker, B. L., Skinner, M., Lewis, T. (eds.) Thrips Biology and Management. NATO ASI Series (Series A: Life Sciences), Vol. 276. Springer, Boston, MA, pp. 453460.

[38] Tsompana, M., Abad, J., Purugganan, M., Moyer, J. W. (2005): The Molecular population genetics of the tomato spotted wilt virus (TSWV) genome. - Molecular Ecology 14(1): 53-66.

[39] Zhong-Z. H., Zhi-Ke, F., Zhi-Jun, Z., Yao-Bin, L., Xiao-Rong, T. (2011): Complete Genome sequence of a tomato spotted wilt virus isolate from China and comparison to other TSWV isolates of different geographic origin. - Annotated Sequence Record 156: 1905-1908.

\section{APPENDIX}

Appendix 1. Comparison of MH367503 (TSWVAntRB) other TSWV isolates and difference ratios

\begin{tabular}{|c|c|c|c|c|c|c|c|c|c|c|c|c|c|c|c|c|c|c|}
\hline MH367503 & & 0,00 & 0,01 & 0,04 & 0,02 & 0,02 & 0,05 & 0,08 & 0,09 & 0,08 & 0,08 & $\overline{0,08}$ & 0,08 & 0,08 & 0,09 & 0,09 & $\overline{0,09}$ & $\overline{0,08}$ \\
\hline HM015520 & 0,00 & & 0,01 & 0,04 & 0,02 & 0,02 & 0,05 & 0,08 & 0,09 & 0,08 & 0,08 & 0,08 & 0,08 & 0,08 & 0,09 & 0,09 & 0,09 & 0,08 \\
\hline HM015521 & 0,01 & 0,01 & & 0,04 & 0,02 & 0,01 & 0,04 & 0,08 & 0,08 & 0,08 & 0,08 & 0,08 & 0,08 & 0,08 & 0,08 & 0,08 & 0,09 & 0,08 \\
\hline HM015516 & 0,04 & 0,04 & 0,04 & & 0,03 & 0,03 & 0,06 & 0,08 & 0,09 & 0,08 & 0,08 & 0,08 & 0,08 & 0,08 & 0,09 & 0,09 & 0,09 & 0,08 \\
\hline AF208497 & 0,02 & 0,02 & 0,02 & 0,03 & & 0,00 & 0,04 & 0,06 & 0,07 & 0,07 & 0,06 & 0,07 & 0,07 & 0,06 & 0,07 & 0,07 & 0,08 & 0,07 \\
\hline HQ830185 & 0,02 & 0,02 & 0,01 & 0,03 & 0,00 & & 0,04 & 0,06 & 0,06 & 0,06 & 0,06 & 0,07 & 0,07 & 0,06 & 0,06 & 0,07 & 0,08 & 0,07 \\
\hline KY250489 & 0,05 & 0,05 & 0,04 & 0,06 & 0,04 & 0,04 & & 0,09 & 0,10 & 0,10 & 0,09 & 0,10 & 0,10 & 0,09 & 0,10 & 0,09 & 0,10 & 0,10 \\
\hline FM163371 & 0,08 & 0,08 & 0,08 & 0,08 & 0,06 & 0,06 & 0,09 & & 0,01 & 0,03 & 0,06 & 0,06 & 0,06 & 0,02 & 0,02 & 0,04 & 0,05 & 0,06 \\
\hline HQ537114 & 0,09 & 0,09 & 0,08 & 0,09 & 0,07 & 0,06 & 0,10 & 0,01 & & 0,04 & 0,05 & 0,05 & 0,06 & 0,02 & 0,03 & 0,04 & 0,05 & 0,06 \\
\hline KM076652 & 0,08 & 0,08 & 0,08 & 0,08 & 0,07 & 0,06 & 0,10 & 0,03 & 0,04 & & 0,05 & 0,05 & 0,05 & 0,02 & 0,01 & 0,04 & 0,05 & 0,05 \\
\hline JF960236 & 0,08 & 0,08 & 0,08 & 0,08 & 0,06 & 0,06 & 0,09 & 0,06 & 0,05 & 0,05 & & 0,01 & 0,01 & 0,05 & 0,05 & 0,04 & 0,05 & 0,01 \\
\hline KM657118 & 0,08 & 0,08 & 0,08 & 0,08 & 0,07 & 0,07 & 0,10 & 0,06 & 0,05 & 0,05 & 0,01 & & 0,01 & 0,05 & 0,05 & 0,04 & 0,05 & 0,01 \\
\hline KY495608 & 0,08 & 0,08 & 0,08 & 0,08 & 0,07 & 0,07 & 0,10 & 0,06 & 0,06 & 0,05 & 0,01 & 0,01 & & 0,05 & 0,05 & 0,04 & 0,05 & 0,01 \\
\hline AY744493 & 0,08 & 0,08 & 0,08 & 0,08 & 0,06 & 0,06 & 0,09 & 0,02 & 0,02 & 0,02 & 0,05 & 0,05 & 0,05 & & 0,01 & 0,03 & 0,04 & 0,05 \\
\hline KT160281 & 0,09 & 0,09 & 0,08 & 0,09 & 0,07 & 0,06 & 0,10 & 0,02 & 0,03 & 0,01 & 0,05 & 0,05 & 0,05 & 0,01 & & 0,04 & 0,05 & 0,06 \\
\hline KU179514 & 0,09 & 0,09 & 0,08 & 0,09 & 0,07 & 0,07 & 0,09 & 0,04 & 0,04 & 0,04 & 0,04 & 0,04 & 0,04 & 0,03 & 0,04 & & 0,02 & 0,04 \\
\hline MG457158.1 & 0,09 & 0,09 & 0,09 & 0,09 & 0,08 & 0,08 & 0,10 & 0,05 & 0,05 & 0,05 & 0,05 & 0,05 & 0,05 & 0,04 & 0,05 & 0,02 & & 0,05 \\
\hline KX898453.1 & 0,08 & 0,08 & 0,08 & 0,08 & 0,07 & 0,07 & 0,10 & 0,06 & 0,06 & 0,05 & 0,01 & 0,01 & 0,01 & 0,05 & 0,06 & 0,04 & 0,05 & \\
\hline
\end{tabular}


Appendix 2a. Amino acid sequencing of the NSm open reading region of MH367503 (TSWVAntRB) isolate (302 AA)

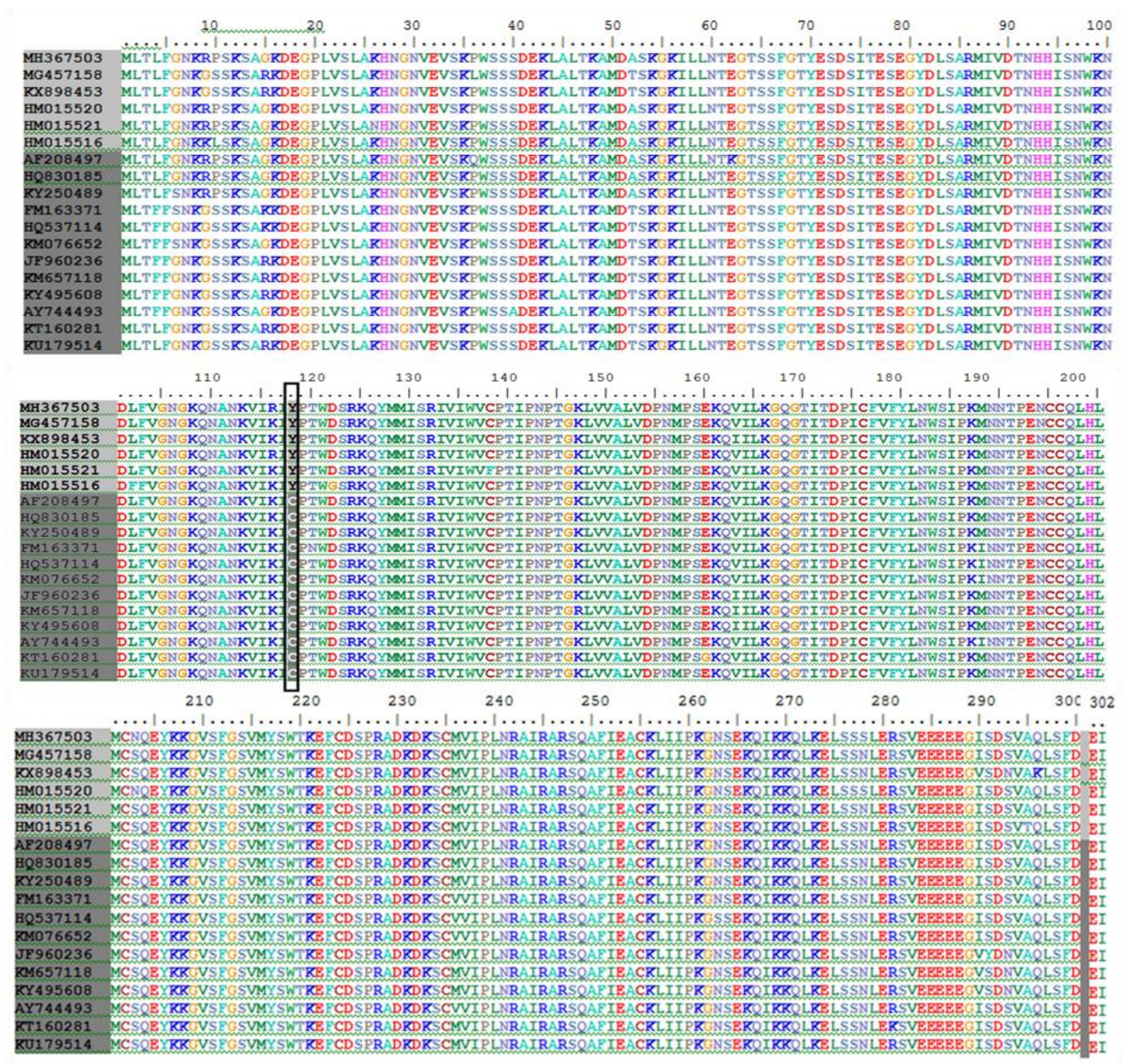


Appendix $2 \boldsymbol{b}$. Amino acid sequencing of the NSm open reading region of MH367503 (TSWVAntRB) isolate (302 AA) and consensus points with other isolates

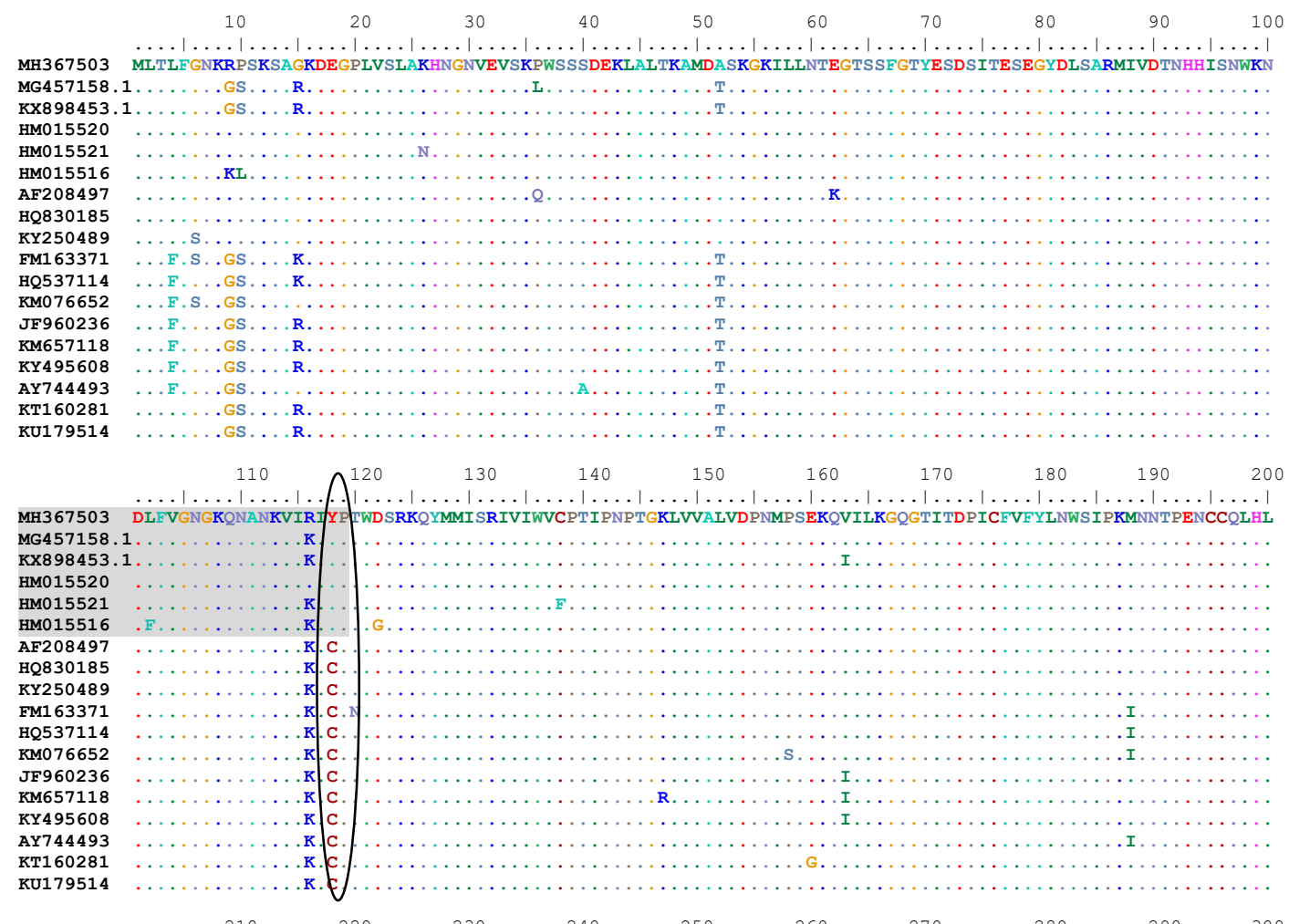

\begin{tabular}{|c|c|}
\hline 1367503 & MCNOEYKKGVSFGSVMYSWTKE FCDSPRADKDKSCMVIPLNRAIRARSOAFIEACKLII PKGNSEKOIKKOLKELSSSLERSVEEEEEGI \\
\hline G457158. & 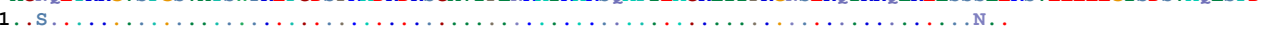 \\
\hline KX898453. & V...N. K. \\
\hline НM015520 & $\ldots$. \\
\hline HМ015521 & ........ \\
\hline Hм015516 & ........... \\
\hline AF208497 & ..s. \\
\hline HQ830185 & $\ldots \ldots \ldots \ldots$ \\
\hline KY250489 & ......... \\
\hline FM163371 & $\ldots \ldots \ldots \ldots$ \\
\hline HQ537114 & $\ldots \ldots \mathrm{N}$. \\
\hline KM076652 & ....v. \\
\hline JF960236 & ........ \\
\hline KM657118 & .....v.n. \\
\hline KY495608 & $\ldots \ldots N$ \\
\hline AY744493 & ..s. \\
\hline KT160281 & .s. \\
\hline KU179514 &.$N$. \\
\hline
\end{tabular}

$\begin{array}{ll}\text { MH367503 } & \text { EI } \\ \text { MG457158.1 } \\ \text { KX898453.1. } \\ \text { HM015520 } & \ldots \\ \text { HM015521 } & \ldots \\ \text { HM015516 } & \ldots \\ \text { AF208497 } & \ldots \\ \text { HQ830185 } & \ldots \\ \text { KY250489 } & \ldots \\ \text { FM163371 } & \ldots \\ \text { HQ537114 } & \ldots \\ \text { KM076652 } & \ldots \\ \text { JF960236 } & \ldots \\ \text { KM657118 } & \ldots \\ \text { KY495608 } & \ldots \\ \text { AY744493 } & \cdots \\ \text { KT160281 } & \ldots \\ \text { KU179514 } & \ldots\end{array}$


Appendix 3. Amino acid sequencing of the Gn-Gc domain of MH367503 (TSWVAntRB) isolate




HM015520

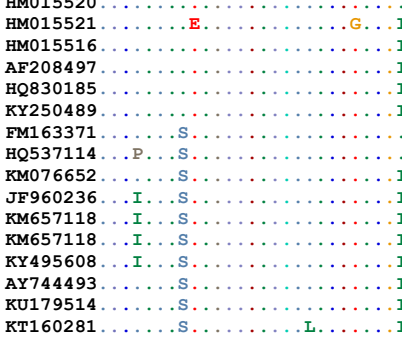

$\begin{array}{lllllllll}210 & 220 & 230 & 240 & 250 & 260 & 270 & 280 & 290\end{array}$ MH367503PITYNSYPTNGTVSLQTVRLSGDCKITKSNEANPYTVSITSPEKIMGYLIKKPGENVEHKVIAFSGSASITETEEMLDGEHNLICGDKSAKIPKANKRVR HM015520 HM015521 HM015516 AF208497 KY250489. FM163371 H0537114.

KM076652

JF960236.

KM657118.

KM657118

KY495608.

AY744493.

KU179514.

KT160281
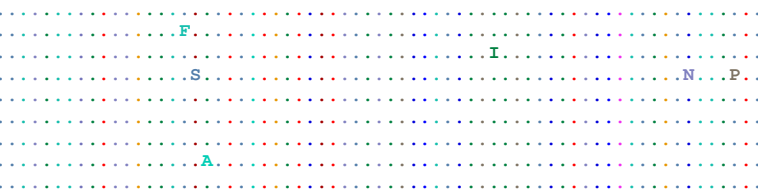

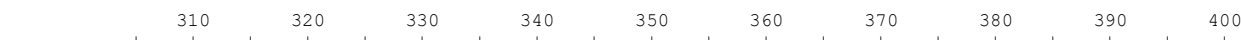
MH367503DCIIKYSKSIYKQTACINFSWIRLILIALIIYFPIRWLVNKTTKPLFLWYDLMGLITYPVLIIINCLWKYFPFKCSNCGNLCIVTHECTKVCICNKSKAS HM015520.

HM015521

.

.

KY250489.

FM163371

HQ537114

KM076652

KM076652

KM657118

KM657118

KY495608 .

AY744493

KU179514

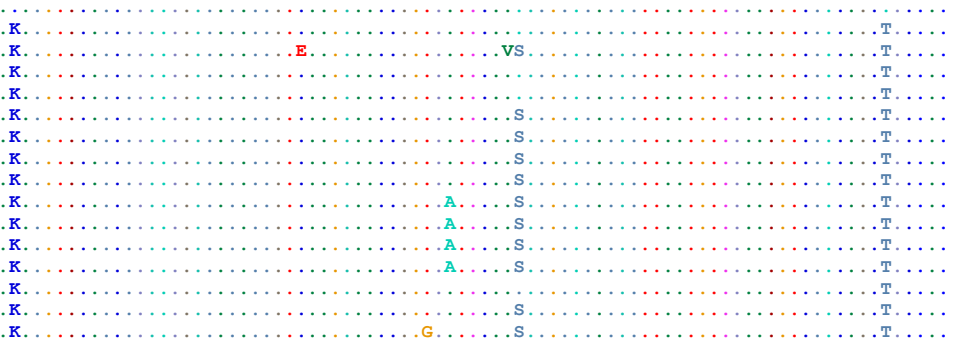

$\begin{array}{rrrrrrrrrr}410 & 420 & 430 & 440 & 450 & 460 & 470 & 480 & 490 & 50\end{array}$

MH367503KEHSSECPILSKEADHDYNKHKWTSMEWFHLIVNTKLSLSLIKFVTEILIGLVILSQMPMPMAQTTQCLSGCFYVPGCPFLVTNKFEKCPEKDQCYCNVK HM015520.

HM015521.

AM015516

.

KY250489.

FM163371

H0537114

KM076652

JF960236.

KM657118.

KM657118.

KY495608.

AY744493.

KU179514.

KT160281.

$\begin{array}{lllllllll}510 & 520 & 530 & 540 & 550 & 560 & 570 & 580 & 590\end{array}$

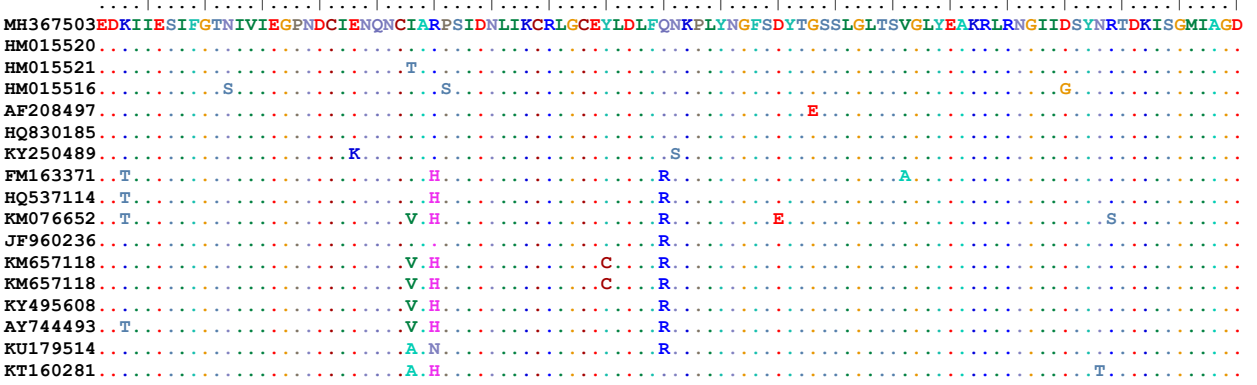

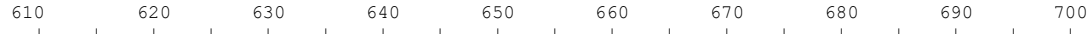

MH 367503 SSDKNETSIAEKILPRQSLIFDSVVD GKYRYMIEQSLIGGGGTIFMLNDKTSETAKKFVIYVKSVGIHYEVSEKYTTAPIQSTHTDFYSTCTGNCDTCRK HM015520.I.......P.N . .

HM015521. L . . . . . P. . .

HM015516. I.......... . .

AF 208497.1.

HQ830185. L . .

(1)

1537114.

Q

JF960236.

(2065718.

KM657118. I .

KY495608. I

AY744493 LN

KT160281. LN. .G...P. . . .
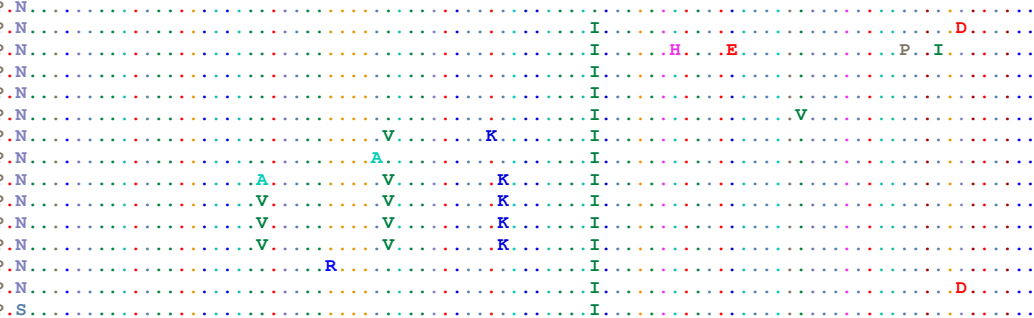

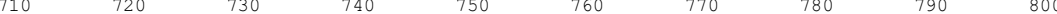

MH367503NQALTGEQDFCITPTSYWGCEEAWCFAINEGATCGFCRNIYDMDKSYRIYSVLKSTIVADVCISGILGGQCSRITEEVYENTLFQADIQADLHNNGITI HM015520

HM015521

HM015516

AF208497

HQ830185

(1)

.

.

.

KM657118 .

KM657118

KY495608

AY744493.

KU179514.

KU179514

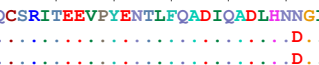

810

820

860

$870 \quad 880$

890

900

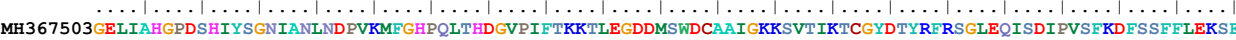
HM015520

HM015521

HM015516D

AF208497

HQ830185.

KY250489

FM163371

HQ537114.

JF960236

KM657118

KM657118

KY495608

KY495608

KU179514.

KT160281

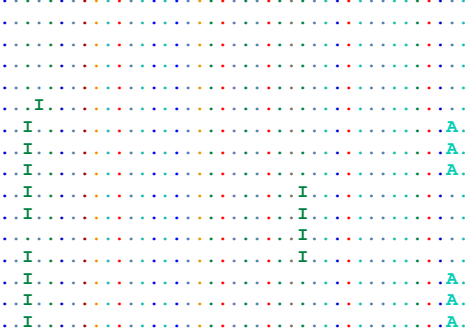



MH367503SLGKLKIVVDLPSDLFKVVRKRSITSTSLNCNGCLICGQGLSCILEFFSDLTFSTAISIDACSLSTYQLAVKKGSNKYNITMFCSANPDKKEMTYYEG HM015520

HM015521

HM015516

AF208497

HQ830185.

KY250489.

FM163371

KQ537114

JF960236

KM657118 .

KM657118.

KY495608

AY744493.

KU179514.

KT160281

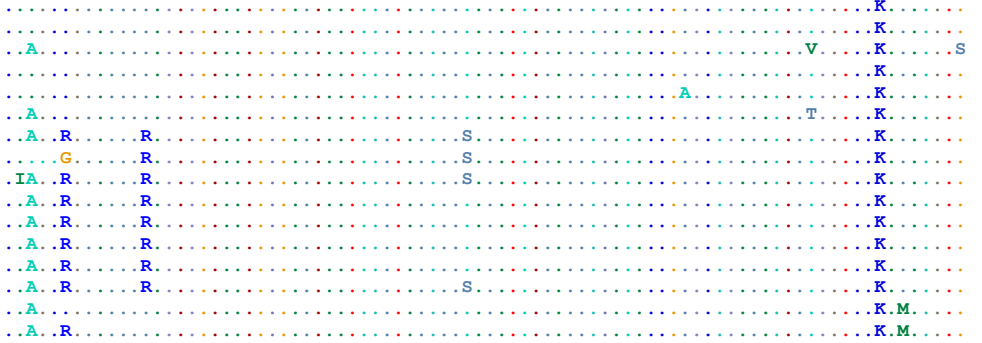

APPLIED ECOLOGY AND ENVIRONMENTAL RESEARCH 17(2):5321-5339.

http://www.aloki.hu • ISSN 15891623 (Print) • ISSN 17850037 (Online)

DOI: http://dx.doi.org/10.15666/aeer/1702_53215339

(c) 2019, ALÖKI Kft., Budapest, Hungary 


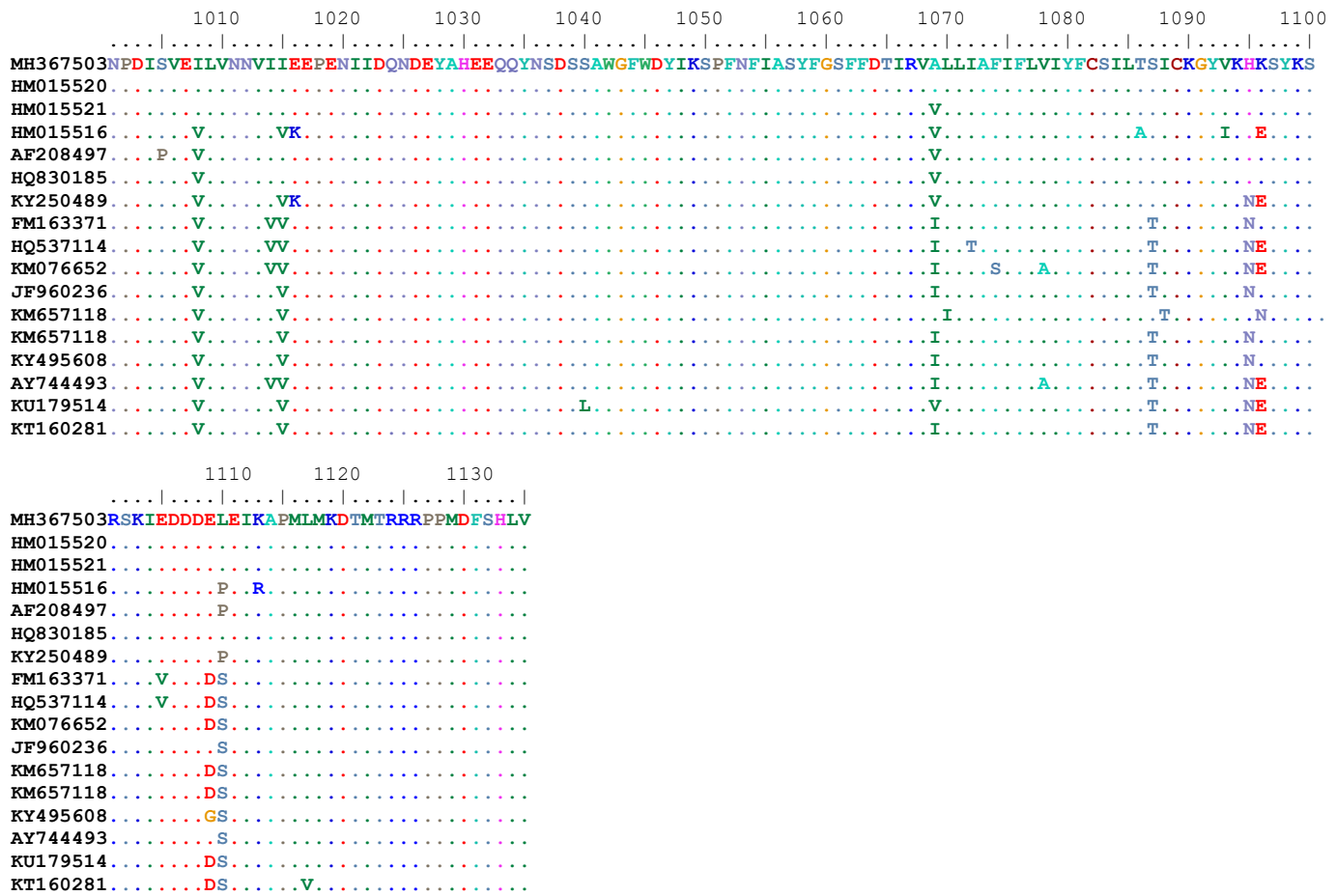

Appendix 4. Results of haplotype analysis of 6 sequences using DnaSP Ver. 5.10.01

\#NEXUS

[File generated by DnaSP Ver. 5.10.01; June 7, 2018]

[Haplotype Data from Data File: aaa.meg]

[Number of sequences: 6 Number of sequences used: 6]

[Number of Sites in the complete Data File: 4825]

[Selected Region: 1-4825]

[Sites with alignment gaps: not considered]

[Invariable sites: included]

BEGIN TAXA;

DIMENSIONS NTAX $=1$;

TAXLABELS

Hap_1;

END;

[Hap\# Freq. Sequences]

[Hap_1: 6 1-6]

[Hap\# Freq. Sequences]

[Hap_1: 6 MH367503.1_TSWVAntRB MH367506.1_TSWVAntRB MH367505.1_TSWVAntRB

MH367501.1_TSWVAntRB MH367504.1_TSWVAntRB MH367502.1_TSWVAntRB]

BEGIN CHARACTERS;

DIMENSIONS NCHAR=4825;

FORMAT DATATYPE=DNA MISSING=? GAP=- MATCHCHAR=.;

MATRIX

Hap_1

AGAGCAATCAGTGCATCAGAAATATACCTATTATACACTTTGCTAAGAATCAATCAACTACA

TTACACAAGCTCCTCTACCTTAGGCTGTTGAACTCAAAATGTTGACTCTTTTCGGTAACAAGA 
GGCCTTCTAAGTCTGCCGGAAAGGATGAAGGTCCTTTAGTTTCACTTGCTAAACATAATGGC AATGTTGAAGTCTCAAAACCATGGTCTTCTTCTGATGAAAAGCTTGCTTTAACCAAAGCCAT GGACGCATCCAAAGGAAAGATACTGTTGAACACTGAGGGAACATCTTCCTTTGGAACCTATG AATCTGATTCTATCACAGAATCAGAGGGTTATGATCTTTCTGCTAGAATGATAGTAGATACA AACCATCATATCTCAAACTGGAAAAATGATCTTTTTGTTGGCAACGGAAAGCAAAATGCTAA TAAGGTTATCAGGATCTATCCAACTTGGGACAGCAGAAAACAATACATGATGATTTCCAGGA TTGTGATATGGGTATGCCCCACTATACCAAACCCTACAGGGAAACTTGTGGTTGCTTTAGTT GATCCCAACATGCCATCTGAAAAGCAAGTCATCCTGAAGGGTCAAGGGACAATAACTGATC CTATCTGCTTTGTTTTTTATCTGAACTGGTCTATTCCGAAGATGAACAACACCCCAGAAAACT GTTGCCAGCTGCATTTGATGTGCAACCAAGAATACAAGAAAGGGGTTTCTTTTGGTAGTGTC ATGTATTCTTGGACAAAAGAGTTTTGCGATTCACCCAGAGCTGATAAAGACAAAAGTTGTAT GGTTATACCTCTAAACAGGGCCATTAGAGCTAGGTCTCAAGCATTCATTGAAGCCTGCAAGC TGATAATTCCTAAAGGAAACAGCGAGAAGCAGATTAAAAAACAGCTTAAAGAATTGAGCTC AAGTCTTGAGAGATCAGTTGAAGAAGAAGAGGAAGGGATTTCTGACAGTGTTGCTCAGTTA TCCTTTGATGAAATATAGTTTTTTAAAACACTTATTTAAGCTTAAATTTCTGTCTATTTTGCAT TTCTAATCCAAAAAACTAAAACAAAAAACAAAAACAAAAAAAGAAAAACAAACAAAAAAA TCAAACCAAAAAACAAAAACAAAATAAGGCTGAAAAGCCAAACTTTGGTCCGAAGACTCTT TTTGTTGTTTTTTGTTTATTTGTATTTTTTGTTTGTTGTTTTTTGTTTATTTCATATTTGCTTTTT ATTAGTCAATGATTGATTCTAAAGATTTTTATATATATAAAATCTTGCTAATATAGAAGATTG AATCAAATTTAATCTGTGACAAGCATCCTCAGACAAGGTGAGAGAAATCCATAGGTGGCCTT CGTCTCGTCATTGTATCTTTCATTAACATAGGGGCTTTGATCTCAAGTTCATCATCATCCTCT ATCTTGGATCTAGATTTATAAGATTTATGCTTTACATATCCTTTACAAATGGATGTCAGAATA GAACAGAAATAAATCACAAGGAAAATGAATGCAATAAGCAGTGCCACTCTGATAGTATCAA AAAATGAGCCAAAGTAACTTGCAATGAAATTGAATGGACTTTTAATATAATCCCAGAAACCC CATGCAGAAGAATCAGAATTATATTGCTGTTCTTCATGAGCATACTCATCATTTTGATCTATT ATATTCTCTGGTTCTTCTATAATAACATTATTAACCAAAATTTCCACAGATATATCCGGATTG CCTTCTGGATACAGTGTCATTTCCTTCTTGTCCGGGTTGGCTGAACAAAACATTGTTATATTG TATTTATTAGATCCTTTTTTAACAGCCAGCTGATAAGTAGATAGAGAGCAAGCGTCTATAGA AATTGCAGTAGAAAATGTCAAATCTGAGAAAAATTCTAAAATGCAAGATAAACCTTGGCCG CATAGAAGACAGCCGTTGCAATTTAAGCTTGTTGAAGTTATGGAAGGTTTTTTAGGAACAAC TTTAAAAAGATCAGATGGAAGATCAACTACAATTTTCAGTTTCCCTAAACTAAAAGATTTTT CCAGGAAAAAACTAGAGAAATCTTTGAAACTAACAGGAATATCTGATATTTGCTCTAAACCA GATCTAAACCTGTATGTGTCATATCCACATGTTTTAATAGTGACTGATTTTTTTCCTATTGCTG CACAATCCCAAGACATGTCATCTCCTTCTAGAGTTTTCTTAGTAAAAATAGGCACTCCATCAT GGGTCAATTGCGGATGACCAAACATTTTCACAGGATCATTCAAGTTTGCAATATTTCCAGAG TAAATATGGCTGTCAGGTCCATGAGCTATTAGTTCACCTATAGTGATACCATCATTATGCAA ATCTGCCTGTATATCAGCTTGAAACAATGTATTTTCATAAGGAACTTCTTCAGTAATCCTTGA GCATTGACCTCCCAAAATACCAGAAATACAAACATCTGCTACTATAGTTGATTTGAGCACTG AATAAATTCTATATGATTTGTCCATGTCATAAATATTTCGACAGAATCCGCATGTAGCACCCT CATTAATTGCAAAACACCAAGCTTCTTCACATCCCCAATAAGAAGTTGGTGTTATACAAAAA TCTTGGAAACCTGTTAAAGCTTGATTTTTCCTGCAAGTGTCGCAGTTTCCTGTACAAGTGGAA TAAAAATCCGTATGGGTGCTTTGGATGGGAGCTGTTGTATATTTTTCTGACACTTCATAATGA ATCCCCACACTTTTGACATAAATCACAAATTTTTTGGCTGTTTCTGAGGTCTTGTCATTTAGC ATGAATATAGTTCCTCCTCCTCCCAAAAGAGATTGTTCTATCATATATCTATATTTCCCGTCT ACAACAGAATCAAAGATTAATGATTGCCTGGGCAGGATGTTCTCTGGTATGCTTGTTTCATTT TTGTCTAAAGAGTCTCCTGCAATCATTCCAGAAATTTTGTCTGTACGATTATAGGAATCTATT ATACCATTTCTCAATCTCTTAGCCTCATACAGACCAACTGATGTTAACCCTAAAGAGCTTCCT GTATAATCCGAAAACCCATTGTACAAAGGTTTGTTCTGAAATAAATCTAGGTATTCGCAACC TAATCTGCATTTTATAAGATTATCAATAGATGGGCGTGCAATGCAATTCTGGTTCTCTATGCA ATCATTAGGACCTTCTATAACAATATTAGTGCCAAAGATACTTTCTATGATCTTGTCTTCTTT TACATTGCAGTAACATTGATCTTTTTCAGGGCATTTCTCAAATTTGTTTGTAACCAAAAATGG ACAGCCTGGAACATAAAAGCATCCACTCAAACATTGGGTTGTTTGAGCCATAGGCATGGGC ATCTGAGACAAAATGACTAAACCTATCAAAATTTCGGTCACAAATTTTAGCAAACTCAAGCT CAGCTTAGTGTTCACTATTAGATGGAACCATTCCATGCTAGTCCACTTATGTTTGTTGTAGTC ATGATCTGCCTCTTTGGACAATATGGGACACTCTGAAGAATGCTCTTTTGAAGCTTTGCTTTT GTTGCAAATGCAGACTTTAGTACACTCATGTGTGACTATGCACAAATTGCCGCAGTTAGAAC ATTTAAATGGGAAATATTTCCATAAGCAATTTATGAGCAATAAGACAGGGTATGTGATCAAG CCCATAAGATCATACCAGAGAAAGAGAGGTTTAGTCGTCTTGTTCACTAACCATCGGATAGG 
GAAATAGATCAACAAAGCTATCAATATCAATCTTATCCAAGAAAAATTGATGCAGGCTGTTT GCTTATAAATACTTTTTGAATATTTGATTATGCAATCTCTGACTCTTTTGTTTGCTTTTGGTAT TTTAGCTGATTTGTCACCGCACAAGAGATTGTGTTCACCATCCAACATTTCCTCGGTAAAAGT GATACTTGCTGATCCAGAAAAAGCTATAACCTTGTGTTCCACATTTTCACCAGGTTTTTTTAT CAAATAACCCATGATCTTCTCAGGGCTAGTGATGCTCACAGTATAGGGATTTGCAAAGTTTG ATTTAGTTATTTTGCAGTCACCAGATAACCTTACAGTTTGTAATGATACTGTTCCATTAGTGG GGTATGAGTTGTAAGTTATAGGATAATTATCTTGTGTCAGGCTTTCTGAAATGAAGAATTTTG TTCCTACTGAAAAATGTCTTTTGTTGTCAAGTTTGGTAATAGGAATAACTGGGACTTTGGAG AATCTCTTTGGCAAATTTAAAGAATTATCACATTTTTCTAAACCTTCTGCTGAATCAGAAACA CAGGAATATATGACACCATTGTTTTCAACTTGATAATAAACATTATAAGTAGATACCCCTTTT ATCTCACATTTTAATGAGGAAGCATTCAAGCAGTTGTTGGGAAGATCCAAAACAGAGATTGT TTTTTGCGTTGCTGGCTCAGTGGAAATAGGGATGGTTGATTTTTCTTCTCGTATCTGGCGGGT TCCAAGAGTCCGAGATTCTAGCATCAGATTAGTTAAAGTCTCCAAGATAGCTTCGCGTTGAA TCGATGCAGCAGTGGGTACCTCATTCTCAGCAGAATCATCATAAATCTCAGGATGATCTCCA CGAATTATTTCTACTTTAGCATCTGTGGCTCTGAAGATCAAGAATGCCAACAAAACAGAACT CAGGGCAATTGTGAAAAGACTCACTTTTACCACTAGTTCTAGTAGTTTTAGAATTCTCATCTT AGATGTCTACCCAGATTACAATGGTTGTGTGATTAATTTCAAGATGTCTGGATTAAGGTTTTT GTTTGCACTGATTGCTCT ; END;

BEGIN CODONS;

CODESET * UNTITLED $=$ Universal: all; END;

BEGIN CODONUSAGE;

END;

BEGIN DnaSP;

Genome= Diploid;

ChromosomalLocation= Autosome;

VariationType $=$ Haplotypes;

DnaSPversion= Ver. 5.10.01;

END; 